\title{
Free the Pharmacist!
}

\author{
Glen Brown
}

$\mathrm{T}$ he complexity and diversity of drug therapy for medical conditions continue to expand, resulting in a need for increased sophistication on the part of all care providers. If pharmacists are to be relevant in contemporary practice, they must possess the knowledge and skills to identify and resolve a great variety of drug-related problems. The requirement for pharmacists to have a range of knowledge and skills has resulted in changes to the curricula of pharmacy schools and has also led to the establishment of training programs and formal roles for advanced practitioners. However, such efforts will be unsuccessful in maximizing the benefit of pharmacists in patient care if these health care providers are encumbered with tasks and roles that do not require their specific skills. As individual professionals, and collectively as pharmacy departments striving to maximize pharmacists' input, we need to identify and eliminate activities and tasks not requiring our skills. In other words, it is time to "free the pharmacist" from inappropriate roles and responsibilities.

In practical terms, this means that we must either stop performing specific functions or find someone or something else to do them. Although it would be most efficient to stop doing things that have no benefit, I hope that our current practice is already focused on essential activities and that there are few opportunities for this type of liberation. Therefore, we must look for ways to "outsource" our work to others or to machines.

An obvious group for assuming a greater role in the noncognitive work of the pharmacist would be pharmacy technicians. In this issue of the CJHP, the Point Counterpoint column presents a discussion about pharmacy technicians having greater roles in the planning and administration of drug distribution systems within institutions. ${ }^{1,2}$ The authors elaborate on some of the benefits of and concerns about this transfer of responsibility. I encourage all readers to review both opinions and consider whether developing this role for technicians would help in freeing them or their colleagues from participation in drug distribution systems.

In addition to this potential role that technicians could fulfill to liberate pharmacists for more direct patient care, the CJHP has previously published numerous papers describing other innovative roles for technicians, including working with pharmacists to support direct patient care activities. For example, the authors of a previous Point Counterpoint column discussed the merits of having technicians obtain medication histories and provide discharge counselling., ${ }^{3,4}$ Others have described a role for technicians in medication reconciliation, whereby they obtain best possible medication histories. ${ }^{5}$ Collection of the data necessary for optimum drug dosing, with warfarin as the prototype medication, has also been successfully transferred to technicians. ${ }^{6}$ Collection of data by a technician on behalf of a pharmacist in a variety of clinical scenarios (e.g., adverse drug reactions, compliance with drug utilization guidelines, duplicate therapies) has been successfully implemented. ${ }^{7}$ The development of these roles for technicians has allowed pharmacists to better utilize their time and to focus their attention on patient care activities that require a pharmacist's expertise and skills.

Similarly, the use of technology (predominantly electronic) can reduce the time and effort involved in obtaining the information needed to identify and resolve drug-related problems. Much like prescribers who need specific information to initiate drug therapy, ${ }^{8}$ pharmacists need information to evaluate the patient's clinical problem, determine the desired outcome, compare therapeutic alternatives, determine a monitoring plan, and educate the patient about drug-related problems encountered. Each one of these steps can be timeconsuming if manual searches and extraction of data are required.

Imagine the time that would be saved if the pharmacist could simply access the institution's clinical database to obtain all of the information in the patient's medical record, including laboratory data, physical monitoring parameters, outpatient drug therapy (best possible medication history), and current therapy. Although the technology to do this exists today, most Canadian institutions cannot afford the costs. Therefore, until this capability is widely available, Canadian pharmacists must explore ways of utilizing electronic devices that could assist in some of these steps. For example, Fox and Felkey have published a series of columns in Hospital Pharmacy describing new electronic devices that facilitate data retrieval for pharmacists. 
Specifically, they highlight the use of mobile devices to store drug or patient information. ${ }^{9,10}$ Discussions about advances in electronics that are applicable to pharmacy practice can be found on websites and blogs. ${ }^{11}$

Through the transfer of tasks to technicians or the use of electronic tools to reduce the time required to complete tasks, pharmacists should be able to "create" additional time for direct patient care activities that require their skills and expertise. By doing so, the benefits to patients should be maximized. All of us should critically evaluate our practices to identify activities that could be transferred. It's time to free the pharmacist!

\section{References}

1. Raymond CB, Santos CE, Caligiuri C. Should pharmacy technician managers be responsible for the drug distribution system within hospital pharmacy departments? The "pro" side. Can J Hosp Pharm 2011;64(3): 218-219.

2. Levesque J. Should pharmacy technician managers be responsible for the drug distribution system within hospital pharmacy departments? The "con" side. Can J Hosp Pharm 2011;64(3):219-220.

3. Saulnier L. Should pharmacy technicians be trained to obtain medication histories and provide discharge counselling? The "pro" side. Can J Hosp Pharm 2008;61(6):441-442.

4. Schoen J. Should pharmacy technicians be trained to obtain medication histories and provide discharge counselling? The "con" side. Can J Hosp Pharm 2008;61(6):442-443.

5. Leung M, Jung J, Lau W, Kiaii M, Jung B. Best possible medication history for hemodialysis patients obtained by a pharmacy technician. Can J Hosp Pharm 2009;62(5):386-391.
6. Weber E, Hepfinger C, Koontz R, Cohn-Oswald L. Pharmacy technicians supporting clinical functions. Am J Health Syst Pharm 2005;62(23): 2466-2472.

7. Mark SM, Saenz R, Youich BE, Weber RJ. Innovative roles for pharmacy technicians: developing and implementing a unit-based clinical support pharmacy technician model. Hosp Pharm 2008;43(11):920-927.

8. Pollock M, Baaldua OV, Dobbie AE. Appropriate prescribing of medications: an eight step approach. Am Fam Physician 2007;15(2):231-236.

9. Felkey BG, Fox BI. Mobilizing care through portable information devices for patients and providers. Hosp Pharm 2010;45(10):801-802.

10. Fox BI, Felkey BG. Portable information appliances: an update. Hosp Pharm 2010;45(5):418-419.

11. Fox BI, Felkey BG. Getting value from blogs and other web resources. Hosp Pharm 2010;45(7):572-575.

Glen Brown, BSC(Pharm), PharmD, FCSHP, BCPS, is a Clinical Pharmacy Specialist, Pharmacy Department, St Paul's Hospital, Vancouver, British Columbia. He is also an Associate Editor with the CJHP.

\section{Address correspondence to:}

Dr Glen Brown

Pharmacy Department

St Paul's Hospital

1081 Burrard Street

Vancouver BC V6H $1 \mathrm{G} 7$

e-mail: gbrown@providencehealth.bc.ca

\section{ON THE FRONT COVER}

\section{Abbey, Saskatchewan}

"The drought is over" is what photographer Amy Smith thought as she snapped this picture of her parents' ranch,

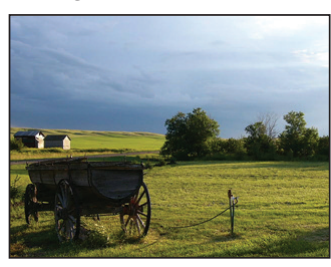

located near Abbey in the southwest corner of Saskatchewan. The wagon depicted here was received as payment in kind for seed grain during the 1930s drought that devastated Saskatchewan. Amy Smith is a recent graduate of the
College of Pharmacy and Nutrition at the University of Saskatchewan and is currently completing her pharmacy residency with the Regina Qu'Appelle Health Region.

The CJHP would be pleased to consider photographs featuring Canadian scenery taken by CSHP members for use on the front cover of the journal. If you would like to submit a photograph, please send an electronic copy (minimum resolution $300 \mathrm{dpi}$ ) to Colleen Drake at cdrake@cshp.ca. 